\author{
ARTIGO \\ do/ https://doi.org/10.22481/rpe.v16i43.6999
}

\title{
PRODUTO EDUCACIONAL COMO RECURSO PEDAGÓGICO PARA VALORIZAÇÃO DA CULTURA AFRICANA E AFRO-BRASILEIRA
}

\author{
EDUCATIONAL PRODUCT AS A PEDAGOGICAL RESOURCE TO VALUE AFRICAN \\ AND AFRO-BRAZILIAN CULTURE
}

\section{PRODUCTO EDUCATIVO COMO RECURSO PEDAGÓGICO PARA VALORAR LA CULTURA AFRICANA Y AFRO-BRASILEÑA}

\author{
Sérgio Teixeira da Silva \\ Universidade Federal de Minas Gerais - Brasil \\ Alexandre Gomes Soares \\ Universidade Federal de Minas Gerais - Brasil
}

\begin{abstract}
Resumo: O presente texto é um recorte ampliado de uma dissertação de mestrado profissional em educação que analisou os sentidos subjetivos que educandos da Educação de Jovens e Adultos, pertencentes às religiões de matrizes africanas, possuem sobre a escola. O objetivo deste artigo é refletir sobre a produção de um material didático denominado Mala Temática Mojubá como requisito básico na formação strictu-sensu. Tal proposta caminha na direção de identificação e na possibilidade de apropriação deste artefato cultural a ser utilizado para valorização das culturas africanas e afrobrasileiras. A proposta metodológica utilizada para a confecção do produto educacional foi a pesquisaação pedagógica apresentada por Franco (2016) para reconfigurar ações pedagógicas coletivas e colaborativas que envolvem a produção de conhecimento no e com os educadores e não apenas para eles, inclusive com o intuito de alcançar uma formação humanística na perspectiva freireana. A elaboração de um artefato cultural como recurso pedagógico que possa contribuir com a implementação da lei 10.639/03 em escolas brasileiras indica uma ação complexa e desafiadora. Um dos desafios consiste em despertar nos educadores a possibilidade de criação, apropriação pedagógica e o uso da Mala Temática Mojubá. Os resultados obtidos demonstraram que o produto confeccionado contribui para a descolonização religiosa nas escolas em que foi destinado. O artefato cultural elaborado é resultado de ações inovadoras no campo educacional, bem como amplia o contexto de atuação pedagógica da docência na educação básica e propicia o reconhecimento da diversidade de sujeitos e saberes no escola.
\end{abstract}

Palavras chave: Cultura africana e afro-brasileira. Mala temática mojubá. Produto educacional.

Abstract: This text is an expanded excerpt from a professional master's dissertation in education that analyzed the subjective meanings that students of Youth and Adult Education, belonging to Africanbased religions, have about the school. The purpose of this article is to reflect on the production of a teaching material called Mala Tematica Mojubá as a basic requirement in strictu-sensu training. Such proposal goes in the direction of identification and the possibility of appropriation of this cultural artifact 
to be used to value African and Afro-Brazilian cultures. The methodological proposal used to make the educational product was the pedagogical action research presented by Franco (2016) to reconfigure collective and collaborative pedagogical actions that involve the production of knowledge in and with educators and not only for them, including with the intention to achieve a humanistic formation in the freirean perspective. The elaboration of a cultural artifact as a pedagogical resource that can contribute to the implementation of law 10.639/ 03 in brazilian schools indicates a complex and challenging action. One of the challenges is to awaken in educators the possibility of creation, pedagogical appropriation and the use of the Mojubá Theme Bag. The results obtained demonstrated that the manufactured product contributes to the religious decolonization in the schools where it was destined. The cultural artifact elaborated is the result of innovative actions in the educational field, as well as expanding the context of teaching teaching in basic education and providing recognition of the diversity of subjects and knowledge in school.

Keywords: African and afro-brazilian culture. Thematic suitcase mojubá. Educational product.

Resumen: Este texto es un extracto ampliado de una disertación de maestría profesional en educación que analizó los significados subjetivos que los estudiantes de Educación de Jóvenes y Adultos, pertenecientes a religiones africanas, tienen sobre la escuela. El propósito de este artículo es reflexionar sobre la producción de un material didáctico llamado Mala Tematica Mojubá como requisito básico en el entrenamiento estricto-sensu. Dicha propuesta va en la dirección de la identificación y la posibilidad de apropiación de este artefacto cultural para ser usado para valorar las culturas africanas y afrobrasileñas. La propuesta metodológica utilizada para elaborar el producto educativo fue la investigación de acción pedagógica presentada por Franco (2016) para reconfigurar acciones pedagógicas colectivas y colaborativas que implican la producción de conocimiento en y con los educadores y no solo para ellos, incluso con la intención lograr una formación humanista en la perspectiva freireana. La elaboración de un artefacto cultural como recurso pedagógico que puede contribuir a la implementación de la ley 10.639/03 en las escuelas brasileñas indica una acción compleja y desafiante. Uno de los desafíos es despertar en los educadores la posibilidad de creación, apropiación pedagógica y el uso de la bolsa temática Mojubá. Los resultados obtenidos demostraron que el producto fabricado contribuye a la descolonización religiosa en las escuelas donde fue destinado. El artefacto cultural elaborado es el resultado de acciones innovadoras en el campo educativo, así como de expandir el contexto de la enseñanza de la enseñanza en la educación básica y proporcionar reconocimiento de la diversidad de asignaturas y conocimientos en la escuela.

Palabras clave: Cultura africana y afrobrasileña; Maleta Temática Mojubá; Producto educativo.

\section{Introdução}

Durante muitos anos, estudos sobre as culturas africanas e afro-brasileiras ficaram às margens do processo de ensino e aprendizagem em instituições educacionais no Brasil. Somente no ano de 2003, especificamente no mês de março, foi decretada a Lei 10.639/03 que estabeleceu a obrigatoriedade do ensino de "História e Cultura Afro-Brasileira" nos currículos escolares, tendo que ser oferecido, obrigatoriamente, pelas disciplinas de Arte, História e Literatura, conforme estabelecido no Artigo 26-A, parágrafo segundo da referida lei. Mesmo após a implantação da lei 10.639/03, pesquisas realizadas por Caputo (2005), Bakke (2011), Oliveira (2014), Vieira (2016), indicam que a cultura africana e afro-brasileira, incluindo as 
religiosidades de matriz africana, em seu aspecto cultural, não proselitista, ainda é pouco abordada por educadores na Rede Oficial de Ensino.

O presente texto é um recorte de uma dissertação de mestrado profissional em educação que analisou os sentidos subjetivos que educandos da Educação de Jovens e Adultos, pertencentes às religiões de matrizes africanas, possuem sobre a escola. O problema de pesquisa perpassou pela constatação da qual, nas escolas públicas, há o privilégio de uma cultura em detrimento de outras, privilegia-se a matriz cultural européia em detrimento das matrizes africanas e indígenas, com isso, instaura-se o silenciamento, a invisibilidade e a exclusão, não somente dos conteúdos escolares que representam as culturas negadas, mas, sobretudo, aos sujeitos que se identificam com estas culturas.

A partir dessa compreensão e tendo em vista a necessidade de oferecer aos educadores das escolas públicas, subsídios que favoreçam o trabalho com as culturas africanas e afrobrasileiras no viés das religiosidades de matrizes africanas, é que foi pensado o produto educacional denominado, "Mala Temática Mojubá". Outro fator importante é que, de acordo com a Coordenação de Aperfeiçoamento de Pessoal de Nível Superior (CAPES), os mestrados profissionais precisam gerar um produto que contribua com as práticas pedagógicas dos docentes em escolas brasileiras.

Assim, o objetivo deste artigo é refletir sobre a produção de um material didático: Mala Temática Mojubá em um Mestrado Profissional na área de Educação. Tal proposta caminha na direção de identificação e na possibilidade de apropriação deste artefato cultural a ser utilizado para valorização das culturas africanas e afro-brasileiras, propiciando aos profissionais da Educação Básica ações didáticas que favoreçam a eliminação dos estereótipos, preconceitos e discriminações contra culturas de origem negra e a promoção da equidade racial na escola.

A proposta metodológica utilizada para a confecção do produto educacional foi a pesquisa-ação pedagógica apresentada por Franco (2016) para reconfigurar ações pedagógicas coletivas e colaborativas que envolvem a produção de conhecimento no e com os educadores e não apenas para eles, com o intuito de alcançar uma formação humanística na perspectiva freireana.

A organização do artigo foi estruturada em quatro momentos: no primeiro, as considerações iniciais que aborda a escola como espaço sociocultural; no segundo momento discorremos sobre a percepção de produto educacional no âmbito do mestrado profissional em educação, no terceiro descrevemos a composição e as sugestões de atividades que o produto educacional oferece e, por último, as considerações finais. 


\section{A escola como espaço sociocultural para a formação cidadã dos sujeitos}

Ao nos referirmos à escola como um espaço sociocultural, alguns questionamentos precisam ser levados em consideração: Será que as escolas valorizam as múltiplas culturas existentes em seus espaços educativos? Os educadores têm preparado suas aulas buscando atender às diferenças e os diferentes que frequentam a escola? Os profissionais da educação conseguem localizar materiais didáticos que promovam os marcadores da diferença?

A partir dessas questões iniciais consideramos necessário repensar o caráter monocultural estabelecido nas escolas. A escola que deveria ser um local democrático e acolhedor acaba por se configurar de forma frequente em um espaço soberano que nega as diversas formas de expressão. Segundo Candau (2000), é preciso ultrapassar a ênfase que se configurou nas escolas em afirmar quase que exclusivamente a hegemonia da cultura ocidental, silenciando vozes e culturas originárias de outros continentes, como as culturas negras e outros grupos marginalizados em nossas sociedades.

Apesar de serem numerosos os movimentos sociais de caráter identitário que indagam a formação docente e respectivamente problematizam o universo escolar, parece que, nas escolas, ainda predomina a cultura ocidental europeia. Contudo, para que a escola ultrapasse essa tendência, é necessário que haja em seus espaços, articulação entre igualdade e diferença. A cultura ocidental predominante na escola impede que outras culturas sejam consideras válidas pela comunidade escolar, principalmente pelos educadores, quando não abordam em suas aulas, temas relativos às culturas africanas e afro-brasileiras.

A pesquisa realizada por Chaves Junior (2015) revela dados surpreendentes sobre o preconceito que educadoras candomblecistas sofrem em escolas públicas ao ministrarem aulas que abordam temáticas afro-brasileiras. Para ele, essas educadoras sofrem a "cultura do ódio", sendo esta, uma prática inquisidora realizada nas escolas com o objetivo de menosprezar as diferenças e os diferentes. Contudo, segundo o pesquisador, é importante que os educadores pertencentes ao Candomblé e a outras religiões de matrizes africanas enfrentem o preconceito e a discriminação, trabalhando, inclusive, sob ameaças, temas que evidenciem as culturas africanas e afro-brasileiras em sala de aula.

Para os educadores e educadoras, adeptos de alguma religião de matriz africana, romper com propostas de ensino monocultural é um grande desafio, pois, além da intolerância, da discriminação e dos preconceitos sofridos por suas identidades religiosas, ainda encontram nas escolas, propostas de currículos exclusivistas, que legitimam a produção e a reprodução de desigualdades múltiplas. Entretanto, é interessante ressaltar que, em meio às dificuldades, os 
educadores que se dispõem a trabalhar com culturas africanas e afro-brasileiras envolvendo as religiões de matrizes africanas; buscam, constantemente, estratégias para vencer os desafios que lhes são apresentados. De acordo com Bakke (2011) a maioria dos docentes que trabalham em escolas públicas não são adeptos das religiões de matrizes africanas. Estes educadores alegam vários motivos para tentar justificar a omissão em desenvolver projetos educativos que contemplam a cultura africana e afro-brasileira na escola.

O que se percebe é que, em escolas públicas, apenas um pequeno grupo de educadores tentam vencer as dificuldades e buscam apresentar propostas que possam contribuir com a implementação da Lei 10.639/2003. Para mudar essa realidade, é preciso que os docentes busquem alternativas na Educação Social. A Educação Social apresenta propostas que contribuem para uma Educação que seja complexa, flexível, dinâmica, respeitadora, dialógica e interativa. Os educadores sociais destacam-se por suas atitudes de comprometimento, dedicação, acolhimento e atenção com os educandos.

Os educadores precisam considerar os educandos como seres que "demandam processos humanizados e educativos, livres das amarras das grades curriculares ou do currículo duro promovido pela docência" (PAIVA, 2015, p. 69). É por isso que, para se aproximarem de uma pedagogia social, os educadores escolares além de conhecer, precisam se comprometer com os sujeitos que se encontram em situação de desvantagem social, com aqueles que têm suas identidades negadas, com os marginalizados dos processos educativos, assim, certamente, se aproximarão bastante das perspectivas esperadas do que seja uma escola democrática. Contudo, ressaltamos que não se deve acreditar que a Educação Social seja uma exclusividade apenas de alguns grupos sociais, pois, conforme Paiva (2015, p. 79), “a Educação Social é para todos e está presente durante toda vida neste ser meio social que se chama humano, e ensinar a educação social, fala do desenvolvimento humano do ser".

É nesse contexto que a escola deve se transformar em espaços educativos cujas pedagogias implicadas em sala de aula se aproximem daquelas concebidas pelos Educadores Sociais. Segundo Paiva (2015, p. 68), “é possível trabalhar o social através da Educação. A Pedagogia Social não consegue pensar Educação sem imbricamento profundo com o social." Neste sentido, Paiva (2015) endossa que "a Pedagogia Social brasileira, que tem a sua origem notadamente na Educação Popular ${ }^{1}$, esta não se propõe a conflitos, a rompimentos, a não ser com o ciclo de marginalização historicamente constituído.” (PAIVA, 2015, p. 69).

\footnotetext{
${ }^{1}$ Para Candau (2000, p. 42), "a Educação Popular que se fala é aquela que se caracteriza pela ênfase no universo cultural do aluno. Menos preocupados com os conteúdos e as disciplinas tradicionais, os educadores populares
} 
É por isso que a Educação Popular e a Educação Escolar formal não devem ser pensadas de forma desarticulada e nem em posições contrárias, é preciso que esse campo da ciência da educação seja trabalhado de maneira articulada. Ainda que Educação Escolar formal tenha prioritariamente propostas pedagógicas e, em alguns aspectos, tenha lacunas na abordagem da diversidade e que, a ênfase da Educação Popular valorize a diversidade cultural dos educandos, é pertinente pensá-las "a partir da articulação das diferentes razões que estão em jogo." (CANDAU, 2000, p. 43). Estas razões estão diretamente relacionadas com as relações de poder estabelecidas na escola, lugar onde se determina quem fala e quem é silenciado, que culturas devem ser reveladas e trabalhadas e quais deverão ser ocultadas e negadas, quais linguagens poderão ser contempladas e quais serão desprezadas, quais sujeitos devem ser invisibilizados e quais serão evidenciados. Não se deve perder de vista que as "relações culturais e étnicas estão permeadas por relações de poder. Daí seu caráter muitas vezes contestador, conflitivo e mesmo socialmente explosivo." (CANDAU, 2000, p. 49).

Os muros construídos na escola em torno dos diferentes, daqueles considerados inferiores por seus pertencimentos identitários revelam o quanto a cultura escolar ${ }^{2}$ encontra-se cristalizada ${ }^{3}$. Os modos de regulação da escola em relação à gestão dos conteúdos dos símbolos e dos ritos, por exemplo, parece estar engessada. A cultura escolar é padronizada, formal e exclusivista. Esse fato impede o compartilhamento de conhecimentos provenientes de outros espaços, como os espaços dos Terreiros, e de outros sujeitos, que por suas singularidades diferentes da "normal”, são excluídos na escola.

Essa forma de regulação excludente, que muitas escolas insistem em adotar, aproximase bastante do que Santos (2009) define como "pensamento abissal”, esse pensamento consiste em dois universos distintos, um visível e outro invisível, sendo que, o primeiro visível encontrase de um lado da linha e o segundo invisível, representa o universo do outro lado da linha. O pensamento abissal impossibilita a presença conjunta dos dois lados, pois de acordo com a configuração da realidade social, o que vemos é que "do outro lado da linha, não há conhecimento real; existem crenças, opiniões, magia, idolatria, entendimentos indutivos ou subjetivos." (SANTOS, 2009, p. 04).

pensam a escola como um espaço onde as camadas populares possam desenvolver um conhecimento capaz de reforçar o seu poder de resistência e de luta."

${ }^{2}$ Segundo Sacristan (1995, p. 97), "a cultura escolar monocultural dominante nas salas de aula é a que corresponde à visão de determinados grupos sociais: nos conteúdos escolares e nos textos aparece poucas vezes a cultura popular, as sobculturas dos jovens, as contribuições das mulheres à sociedade, as formas de vida rurais, e dos povos desfavorecidos."

3 "A dinâmica cristalizada da cultura escolar apresenta uma enorme dificuldade de incorporar as diferentes formas de aquisição de conhecimentos, as diversas linguagens e expressões culturais e as novas sensibilidades presentes de modo especial nas novas gerações e nos diferentes grupos culturais.” (CANDAU, 2000, p. 53). 
Para romper com o "pensamento abissal", as escolas precisam modificar o fazer pedagógico, reorientá-lo de forma que alguns grupos sociais não sejam injustiçados. As ações pedagógicas precisam reconhecer outras possibilidades de ensino e aprendizagem, nas quais o conhecimento não seja linear, abrindo possibilidades para conexões com saberes provindos dos Terreiros de Candomblé e Umbanda. Ao considerar esses espaços socioculturais como aliados, a escola poderá compartilhar saberes, valores e formas diferenciadas de ser e estar no mundo.

Os educadores que se dispuserem a compartilhar em sala de aula saberes provenientes de outros espaços educativos, como os Terreiros, por exemplo, no resgate de culturas africanas e afro-brasileiras, precisam estar dispostos a confrontar a monocultura dos currículos e das práticas pedagógicas. De acordo com Silva (1995), confrontar os currículos escolares é sinônimo de contestá-los, principalmente porque, estes, apresentam estreitas relações com o conhecimento estabelecido na escola, pois estão envolvidos com relações de poder que legitimam desigualdades escolares, evidenciam algumas identidades e invisibilizam outras. Ao considerarem em suas aulas os saberes dos Terreiros, por exemplo, os educadores poderão dar visibilidade não somente às culturas africanas e afro-brasileiras, mas também, aos sujeitos detentores dessas culturas.

É por isso que o currículo não deve ser visto como documento burocrático expositório de conteúdos, mas, sobretudo, como uma relação social, uma vez que a produção do conhecimento envolve relações entre pessoas, saberes e lugares distintos. De acordo com Silva (1995)

É importante ver o currículo não apenas como sendo constituído de fazer coisas, mas também, vê-lo como fazendo coisas às pessoas. $\mathrm{O}$ currículo é aquilo que nós, professores e estudantes fazemos com as coisas, mas, é também aquilo que as coisas fazem a nós. (SILVA, 1995, p. 194).

Compreender que o currículo produz conhecimento a toda comunidade escolar é o primeiro passo para que os docentes oportunizem na prática, saberes e conhecimentos excluídos na e pela escola, vencendo assim "o epistemicídio, isto é, o extermínio de formas subordinadas de conhecer.” (SILVA, 1995, p. 195). Para vencer o epistemicídio nas escolas, é preciso considerar a necessidade de implementar políticas educacionais que busquem recuperar as culturas negadas. Uma das alternativas que podem ser significativas para o desenvolvimento de práticas pedagógicas mais plurais que considerem a diversidade do diálogo e do respeito às diferentes culturas existentes na escola seria implicar as bases do multiculturalismo crítico de resistência no fazer pedagógico. Propor o multiculturalismo crítico significa romper com relações culturais, sociais e institucionais forjadas no interior das instituições de ensino para 
inferiorizar, desvalorizar e excluir as diversidades culturais dos diferentes sujeitos ali presentes. Segundo Mclaren (1997), para adotar o multiculturalismo crítico de resistência, as escolas precisam realizar uma profunda reforma curricular. Para ele, essa reforma só acontece quando os educadores passam a dar visibilidade às culturas marginalizadas e quando os estudantes são encorajados a produzir suas próprias leituras de oposição do conteúdo curricular. "Reforma curricular significa reconhecer que grupos estão diferencialmente situados na produção do conhecimento superior ocidental." (MCLAREN, 1997, p. 145).

Ao reconstruir o currículo, abrem-se oportunidades para que vozes silenciadas sejam ouvidas e educandos antes emudecidos possam dialogar livremente sem medo de serem confrontados e ridicularizados por suas diferentes formas de pensar. Ao vencer o medo de se expressar, por meio do diálogo, os sujeitos têm a oportunidade de confrontar as vozes que debilitam suas identidades, que colocam em cheque suas verdades, certezas, crenças e culturas. O diálogo é necessário, porque, além de oportunizar diversos saberes, orienta e reorienta a relatividade do conhecimento. Conceber a escola desta forma possibilita torná-la "um espaço de busca, construção, confronto, prazer, desafio, conquista de espaço, descoberta de diferentes possibilidades de expressão e linguagens, aventura, organização cidadã, afirmação da dimensão ética e política de todo processo educativo.” (CANDAU, 2000, p. 14).

As mudanças estruturais nos currículos escolares somado à assunção do multiculturalismo crítico de resistência são importantes para que as escolas reconheçam as culturas africanas e afro-brasileiras, deixando de ser assim, um espaço etnocêntrico, hegemonicamente europeu. É nesse contexto que o produto educativo denominado "Mala Temática Mojubá" é apresentado, como mais uma alternativa de valorização e de reconhecimento às culturas negadas em escolas brasileiras.

\section{A percepção de produto educacional no âmbito do mestrado profisssional}

A percepção de produto educacional no âmbito do mestrado profissional suscita saberes, práticas pedagógicas, objetivos de aprendizagem e delineamento da natureza deste artefato cultural. Aspectos estes, mencionados anteriormente que se relacionam com a pesquisa de Chisté (2019) em sua trajetória de avaliação de produtos educacionais. De acordo com a Portaria Normativa nº 17 de 28 dezembro de 2009 há uma descrição no $§ 3^{\circ}$ que

[...] o trabalho de conclusão final do curso poderá ser apresentado em diferentes formatos, tais como dissertação, revisão sistemática e aprofundada da literatura, artigo, patente, registros de propriedade intelectual, projetos 
técnicos, publicações tecnológicas; desenvolvimento de aplicativos, de materiais didáticos e instrucionais e de produtos, processos e técnicas; produção de programas de mídia, editoria, composições, concertos, relatórios finais de pesquisa, softwares, estudos de caso, relatório técnico com regras de sigilo, manual de operação técnica, protocolo experimental ou de aplicação em serviços, proposta de intervenção em procedimentos clínicos ou de serviço pertinente, projeto de aplicação ou adequação tecnológica, protótipos para desenvolvimento ou produção de instrumentos, equipamentos e kits, projetos de inovação tecnológica, produção artística, sem prejuízo de outros formatos, de acordo com a natureza da área e a finalidade do curso, desde que previamente propostos e aprovados pela CAPES. (BRASIL, 2009, p.21, grifos nossos).

A partir da exemplificação das possibilidades de produtos no âmbito do mestrado profissional em educação, considera-se que a produção de materiais está vinculada a concepções pedagógicas que dialoguem com a legislação educacional em curso, com os sujeitos que estão inseridos na escola considerando suas especificidades, seus marcadores sociais. Nessa direção, compreendemos uma prática docente reflexiva que busca o reconhecimento das práticas culturais, religiosas dos educandos, educadores e gestores desta modalidade. A concepção de educação que defendemos, baseia-se na inserção e importância dos recortes etários, religiosidade, gênero diversidade sexual, étnico-racial.

O desenvolvimento de um material educativo pressupõe diversos desafios a serem analisados, pois, parte inicialmente de concepções pedagógicas que os docentes propõem em relação com suas experiências, narrativas, vivências no cotidiano da sua formação e de sua prática pedagógica. Estas considerações nos levam a pesquisar sobre a elaboração de um produto educacional possibilitando uma nova metodologia que esteja em consonância com o que Franco (2016) denomina de pesquisa-ação pedagógica (PAPe), descrita por ser,

[...] uma modalidade de pesquisa-ação, voltada à formação continuada de professores protagonistas, críticos-reflexivos, empoderados, capazes de transformarem a si e às suas circunstâncias. Na perspectiva da PAPe, a proposta é que os participantes, através da superação da consciência ingênua, renovem a percepção das suas condições de olhar do sujeito sobre a situação em vivem e que os oprimem. (FRANCO, 2016, p. 513).

A partir dessa percepção entendemos que quando os educadores conseguem modificar as concepções de sua profissionalidade e passam a exercer ações práticas educativas, fazendo com que os educandos incorporem a aprendizagem em suas vidas, ocorre segundo a autora, um fenômeno chamado de "produção de rupturas cognitivas" no qual o conhecimento é produzido não apenas para o educador e educando, mas para os todos os sujeitos envolvidos no processo de ensino e aprendizagem. Franco (2016) enfatiza que a metodologia de pesquisa-ação pedagógica rompe com o círculo negativo que envolve a formação precária, a pauperização das 
condições de trabalho docente, o esgotamento da racionalidade pedagógica, e, principalmente, as condições de alienação e desumanização sofrida por educandos e educadores em instituições de ensino. Ao romper esse ciclo negativo de formação, os educadores inserem-se numa perspectiva de "aprendizagem/investigação coletiva, colaborativa, contínua, de forma a acabar com a letargia e despersonalização dos processos de vida e formação de professores da educação básica." (FRANCO, 2016, p. 514).

O rompimento do ciclo negativo de formação conduz os educadores a enriquecerem suas ações práticas educativas por meio da criação de materiais que envolvem elementos que facilitam o aprendizado dos educandos. Nessa direção, é imprescindível que os docentes elaborem produtos educacionais que contribuam com suas práticas pedagógicas, que sejam compatíveis com suas propostas didáticas e que, a aceitabilidade dessa materialidade os conduza a novos olhares na educação. É por isso que, os produtos educacionais precisam ser testados e avaliados, a prototipagem, por exemplo, é um procedimento interessante que pode ser entendido como uma experimentação da primeira versão dos materiais elaborados pelos educadores.

Ao considerar a avaliação dos produtos educacionais, o pesquisador uruguaio Gabriel Kaplun (2002) desenvolveu três eixos analíticos para avaliá-los, tais como: conceitual, pedagógico e comunicacional. No que tange ao eixo conceitual e de forma sintética considerase um aprofundamento sobre o objeto e o conhecimento dos agentes em relação ao tema que constituirá o material educativo, bem como características e sondagens a quem se propõe os materiais. O eixo pedagógico tem como pressuposto o convite para cursar uma trajetória pedagógica que abarque as percepções dos sujeitos, a abertura para dialogar sobre concepções de mundo, e possíveis lacunas em relação ao tema de forma gradativa no intuito de ampliar os saberes com aporte teórico da área. No eixo comunicacional encontra-se o conjunto de artefatos técnicos e gráficos que se propõem a concretizar por meio de uma linguagem específica a produção do material educativo. Diante do exposto, delineamos a origem do material educativo Mala Temática Mojubá.

A Mala Temática Mojubá, cujo termo "Mojubá” significa respeito à ancestralidade africana, é um artefato cultural preparado para ser um recurso didático que oferecerá suporte necessário à implementação da Lei 10.639/03 em instituições de ensino. A confecção de um produto educacional que tenha função pedagógica e que proporcione a mediação de conhecimento em escolas da Educação Básica é uma exigência dos Programas de Mestrado Profissional. A Mala Temática Mojubá, foi organizada como um recurso capaz de valorizar as culturas africanas e afro-brasileiras com ênfase nas religiões de matrizes africanas (Candomblé 
e Umbanda). Todos os objetos nela contidos estão relacionados com aspectos culturais africanos e afro-brasileiros, bem como com a cultura popular. Na Mala Temática, os educadores poderão dispor de uma coletânea de obras que trazem propostas lúdicas de aprendizagem que envolve os valores civilizatórios afro-brasileiros, favorecem a contação de histórias e o conhecimento sobre culturas afro-brasileiras na perspectiva da descolonização religiosa da educação.

\section{Figura 1: Mala Temática Mojubá}

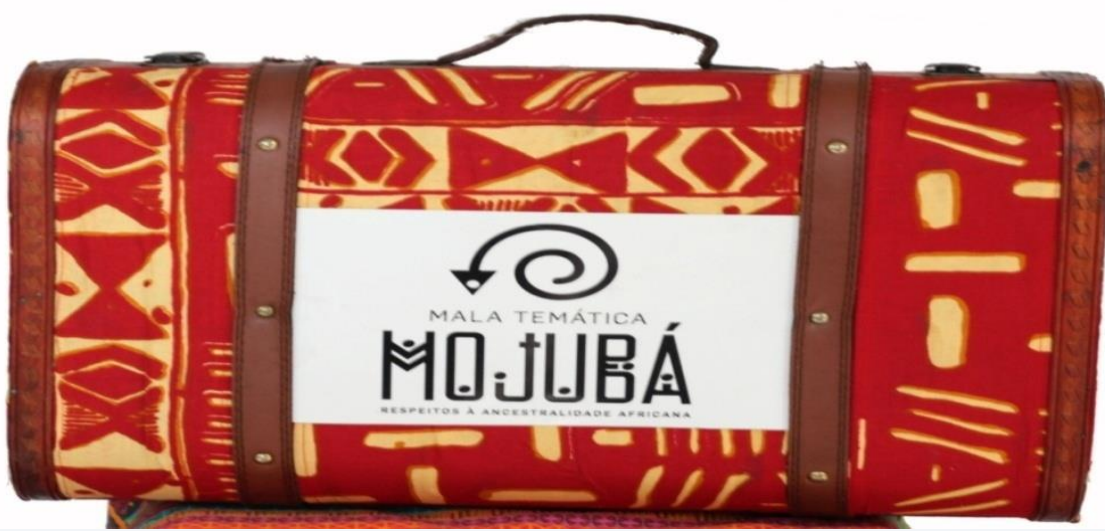

Fonte: Acervo pessoal do autor

Figura 2: Mala Temática Mojubá (parte interna)

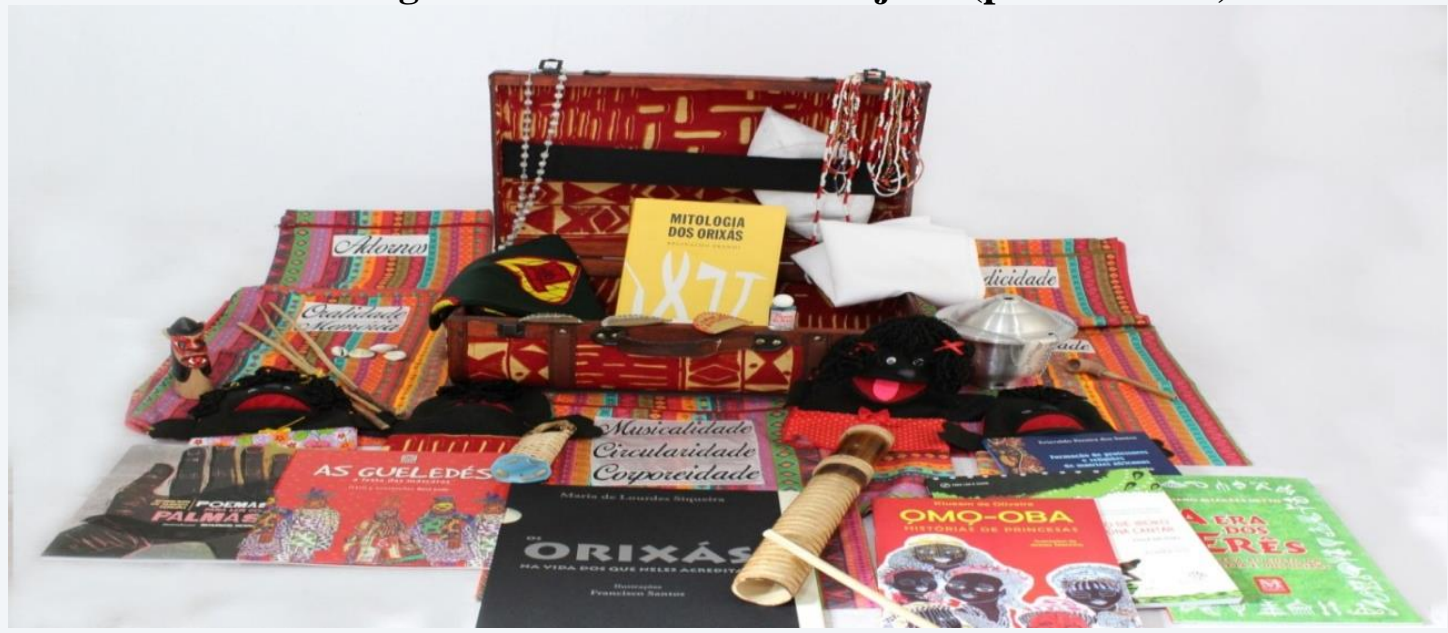

Fonte: Acervo pessoal do autor

É importante ressaltar que na Mala Temática descrita, há obras que ampliam o diálogo sobre a formação de professores no contexto das religiões de matrizes africanas, e também, editoriais que trazem explicações sobre cada símbolo nela contido, assim como algumas legislações das esferas, municipal, estadual e nacional que subsidiam o trabalho docente quanto ao trato de temas que envolvem a cultura africana e afro-brasileira.

$\mathrm{O}$ artefato cultural apresentado trata-se de um modelo que poderá servir de exemplo para que outros educadores preparem sua própria Mala Temática, portando materialidades a 
gosto do docente, bem como legislações específicas dos estados e municípios em que as instituições de ensino estiverem inseridas. O quadro 1 a seguir, especifica os elementos que compõem a Mala Temática:

\section{Quadro 1: Composição da Mala Temática}

\begin{tabular}{|lll}
\hline COMPOSIÇÃO DA MALA TEMÁTICA: Objet \\
\hline & & \\
Aguidavis & Caxixi & Patuás \\
Bonecos de fantoche & Eketé & Perfume \\
Búzios & Fios de contas & Postais \\
Cachimbo & Incensário & Terço \\
Carranca & Máscaras & Turbante
\end{tabular}

\section{COMPOSIÇÃO DA MALA TEMÁTICA - Obras literárias e científicas e cartões postais}

Livro: A Era dos Erês - Uma Era ao culto da natureza e dos orixás - Adriano Bitarães Netto

Livro: As Gueledés - A festa das máscaras - Raul Lody

Livro: Formação de professores e religiões de matrizes africanas: um diálogo necessário - Erisvaldo pereira dos Santos

Livro: Omo-Oba - Histórias de princesas - Kiusam de Oliveira

Livro: Os Orixás na vida dos que neles acreditam - Maria de Lourdes Siqueira

Livro: Mitologia dos orixás - Reginaldo Prandi

Livro: Num Tronco de Iroko vi a Iúna cantar - Erika Balbino

Livro: Poemas para ler com palmas - Edmilson de Almeida Pereira

\section{COMPOSIČ̃̃O DA MALA TEMÁTICA - Cosmogonias}

Grega, Ioruba, Judaico-Cristã

\section{COMPOSIÇÃO DA MALA TEMÁTICA - Legislações}

Lei 4.737 de 24/06/2015 - Plano Municipal de Educação de Contagem/ Minas Gerais

Lei 10.639 de 09/01/2003 - Inclusão no currículo da Rede de Ensino a obrigatoriedade da temática "História e cultura Afro-Brasileira"

Lei 9.394 de 20/12/1996 - Estabelece as Diretrizes e Bases da Educação Nacional

Lei 11.635 de 27/12/2007 - Estabelece o Dia Nacional de Combate à Intolerância Religiosa

Diretrizes Curriculares Nacionais para a Educação Étnico-Raciais e para o Ensino de História e Cultura AfroBrasileira e Africana (2004)

Parâmetros Curriculares Nacionais de 1997- Temas transversais

Declaração Universal dos Direitos Humanos

É pertinente destacar que os temas relacionados com as culturas africanas e afrobrasileiras devem ser explorados ao longo de todo ano letivo pelos educadores de todas as disciplinas, mesmo que exista obrigatoriedade de algumas. Porém, existem datas e momentos que propiciam o desenvolvimento de atividades relacionadas com as religiões de matrizes africanas em sala de aula. É bastante oportuno que as atividades sejam realizadas no Dia Nacional do Combate à Intolerância Religiosa (21 de janeiro), caso os educandos e educadores estejam em férias a data poderá ser lembrada em outro momento do ano letivo. 
As atividades podem ser preparadas nas semanas que antecedem o período carnavalesco, haja vista que o carnaval simboliza a maior festa popular brasileira e apresenta características oriundas das tradições religiosas de matriz africana. Trabalhos podem ser desenvolvidos no dia 13 de maio que faz menção à Abolição da Escravatura no Brasil. Os docentes podem trabalhar ainda no dia 20 de novembro que se comemora o Dia Nacional da Consciência Negra e no dia 02 de dezembro que é o Dia Nacional do Samba. Nada impede que os educadores desenvolvam atividades com a Mala Temática em datas diferentes das sugeridas. Sempre que os conteúdos a serem trabalhados estiverem relacionados com as culturas africanas e afro-brasileiras e, estando estes, em consonância com alguma materialidade constante na Mala Temática, esta poderá ser utilizada.

Antes de apresentar a Mala Temática aos estudantes, é importante que os educadores já tenham abordado os temas em suas aulas. As atividades que fazem menção aos objetos, obras e demais símbolos terão mais sentido para os educandos durante a culminância de projetos pedagógicos. É recomendável que, ao trabalhar com a Mala Temática, o educador prepare a sala de aula antecipadamente em forma de círculo, propiciando um ambiente favorável à interação de todos, além de dar ênfase à circularidade como valor civilizatório afro-brasileiro.

\subsection{Metodologia de trabalho com a Mala Temática}

Após ter abordado alguns temas referentes às culturas africanas e afro-brasileiras, o educador, ao levar a Mala Temática para a sala de aula, poderá iniciar as atividades apresentando-a aos educandos e, logo após, pedir que cada um pegue um objeto. Após tocá-lo, observá-lo e senti-lo, os educandos deverão descrever por escrito o que o objeto representa e, posteriormente, o texto será lido em voz alta para que todos possam ouvir.

O momento da abertura da Mala Temática, da retirada dos objetos e dos comentários realizados pelos educandos, será registrado pelo educador, que deverá estar atento aos sentidos que os estudantes atribuirão a cada símbolo, que conceitos formarão, que emoções deixarão transparecer, que palavras pronunciarão e que reações vão esboçar. A partir dessas observações e após as leituras dos textos produzidos pelos estudantes, o educador começa a explicar o que os símbolos representam para as culturas africanas e afro-brasileiras, neste momento, terá a oportunidade de demonstrar aos educandos a diversidade cultural, além de desconstruir preconceitos e estereótipos a partir dos comentários pejorativos que supostamente podem ser pronunciados ou registrados por algum estudante. 
Além dessa possibilidade de trabalho, o educador poderá trabalhar com os artefatos de forma inversa à que foi apresentada. Ao invés de pedir para os estudantes retirarem os símbolos, ele mesmo vai retirando-os da Mala Temática e explicando o seu significado, correlacionandoos com as culturas africanas e afro-brasileiras. Os postais existentes na Mala Temática que caracterizam cada objeto nela contido, também poderão ser utilizados, eles deverão ser distribuídos aos educandos, e, na medida em que o educador vai retirando os artefatos da mala, os educandos que estão com o postal relacionado àquele artefato o identificam e leem no verso do cartão seu significado. Dessa forma, o educador vai contextualizando as leituras, esclarecendo as dúvidas, ao mesmo tempo em que desconstrói intolerâncias que, por ventura, possam se apresentar por meio das falas, atitudes e olhares dos estudantes.

\subsection{Sugestões de atividades com alguns objetos contidos na Mala Temática}

A seguir serão apresentadas algumas sugestões de atividades que poderão ser desenvolvidas pelos educadores a partir da variedade de possibilidades que este recurso pedagógico oferece.

\subsubsection{Atividades com máscaras africanas}

A confecção de máscaras (Figura 2), com os estudantes é uma atividade lúdica e interativa que tem o objetivo de valorizar a cultura dos povos africanos. Após contextualizar em aula sobre a importância e utilização que as máscaras possuem para esses povos, e ao término da leitura da obra "As Gueledés" de Raul Lody, constante na Mala Temática, o educador poderá propor aos educandos que construam suas próprias máscaras. Para isso, é preciso providenciar o lugar e os materiais necessários para a realização da tarefa.

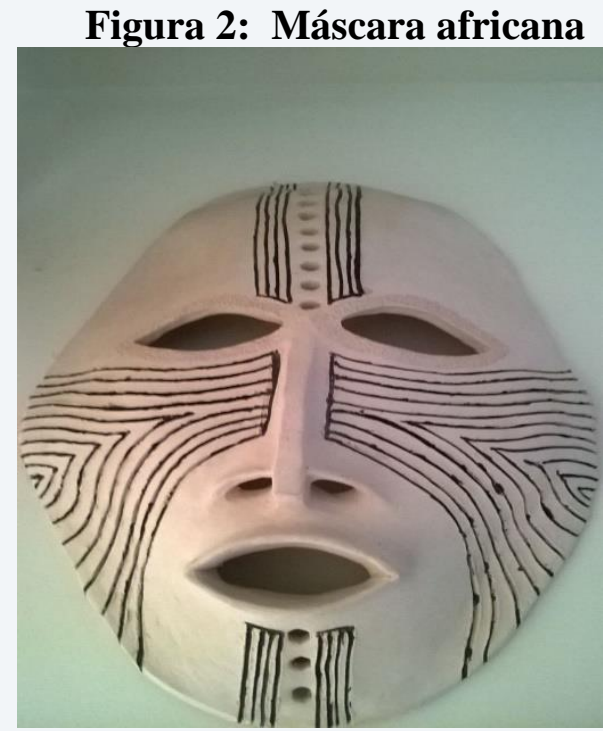

Fonte: Acervo pessoal do autor 


\subsubsection{Atividades com cosmogonias}

Após explicar o conceito de cosmogonia (Figura 3), é interessante que os educadores levem os educandos a refletirem sobre a importância das histórias, de vários povos, que explicam a origem do universo, da natureza, da criação dos seres humanos e demais seres vivos. O educador poderá fazer algumas perguntas para os estudantes com a intenção de constatar qual é a cosmogonia predominante entre eles. Logo após, o educador registra as respostas, na medida em que for explicando, demonstra que existem outras formas de compreensão acerca da criação do universo e dos seres vivos. Após essa contextualização, o educador pode contar a história cosmogônica dos povos iorubanos, cristãos e gregos, possibilitando aos educandos conhecerem diversas crenças, além de incitar o respeito às diferenças.

\section{Figura 3: Cosmogonias Iorubá; Judaico-Cristã e Grega}
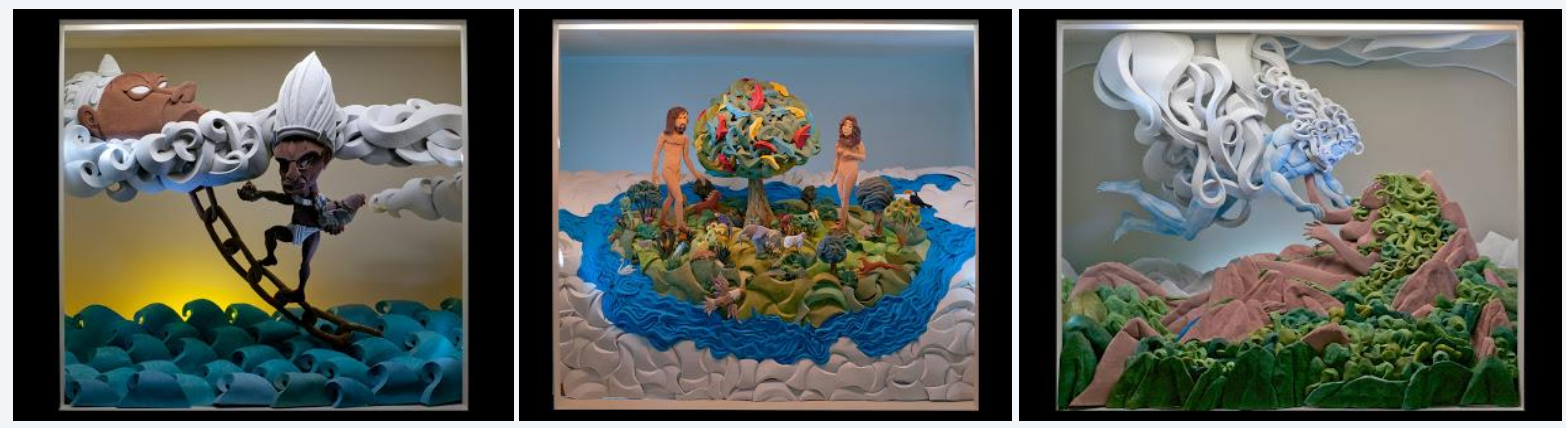

Fonte: https://www.ufmg.br/espacodoconhecimento/cosmogonias-e-cosmologia/

\subsubsection{Atividades com os bonecos de fantoche}

Com objetivo de explorar a oralidade como valor civilizatório afro-brasileiro, os bonecos de fantoche poderão ser utilizados pelos educadores para contação de histórias africanas. A Mala Temática traz várias obras literárias que contribuem com a realização desta atividade, tais como: Omo-Oba: história de princesas, Mitologia dos Orixás, A Era dos Erês, Nun Tronco de Iroko Vi A Iúna Cantar. Os bonecos de fantoche (Figura 4) representam importantes recursos que os educadores têm em mãos para enfatizar a tradição oral que é fortemente valorizada pelos povos africanos. Becker (2013) ressalta que "os fantoches trazem à tona um novo universo. Um boneco ganha voz e vida própria nas mãos dos educadores que contam uma história contagiando os educandos com a magia e fantasia através dos movimentos." (BECKER, 2013, p. 04). 
Figura 4: Bonecos de fantoche

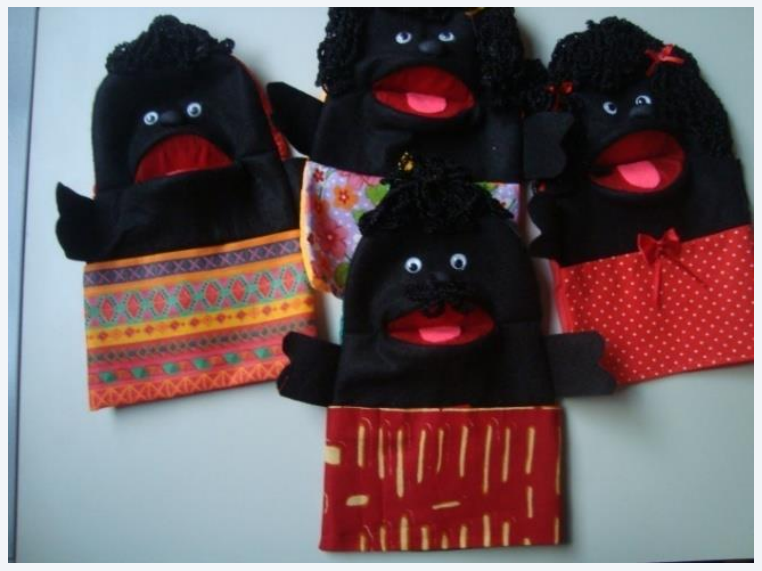

Fonte: Acervo pessoal do autor

\subsubsection{Atividades com caxixi}

Instrumento de percussão em diversos gêneros musicais no Brasil e no mundo, o caxixi é originário do continente africano. Segundo Brandão (2008) o caxixi é utilizado em alguns Terreiros de Candomblé, servindo de acompanhamento ao berimbau na roda de capoeira. Conforme o tamanho, seu som é grave, médio ou agudo. Como se trata de um instrumento que garante a pulsação rítmica é encontrado com frequência na música brasileira e também na música pop internacional. Caxixi quer dizer palma da mão, no idioma quimbundo. É um instrumento na forma de uma cesta de vime, com sementes ou pedrinhas no seu interior, e tendo como base um pedaço de cabaça. Este instrumento é muito fácil de ser confeccionado, o objetivo de confeccionar um caxixi é o de valorizar a musicalidade como um dos valores civilizatórios afro-brasileiros. Além de ser uma atividade lúdica, desperta nos educandos o interesse pela arte e pelas expressões corporais.

\section{Figura 5: Caxixi}

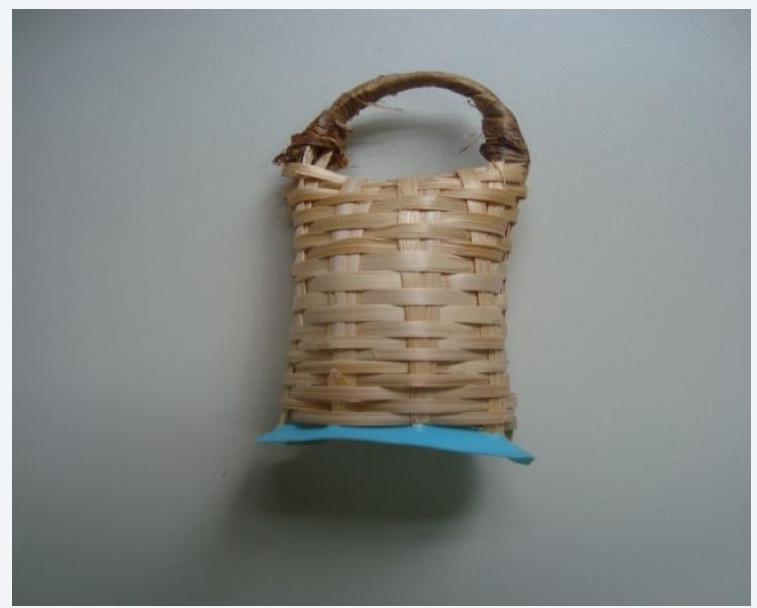

Fonte: Acervo pessoal do autor 


\subsubsection{Sugestões de obras literárias e científicas que podem ser utilizadas pelos educadores}

Todas as obras demonstradas na figura 6 a seguir, podem ser utilizadas pelos educadores para enriquecer os conhecimentos sobre as culturas africanas e afro-brasileiras, os textos contribuem ainda para o desenvolvimento de diversas atividades com educandos da educação infantil ao ensino médio.

Figura 6 - obras literárias e científicas
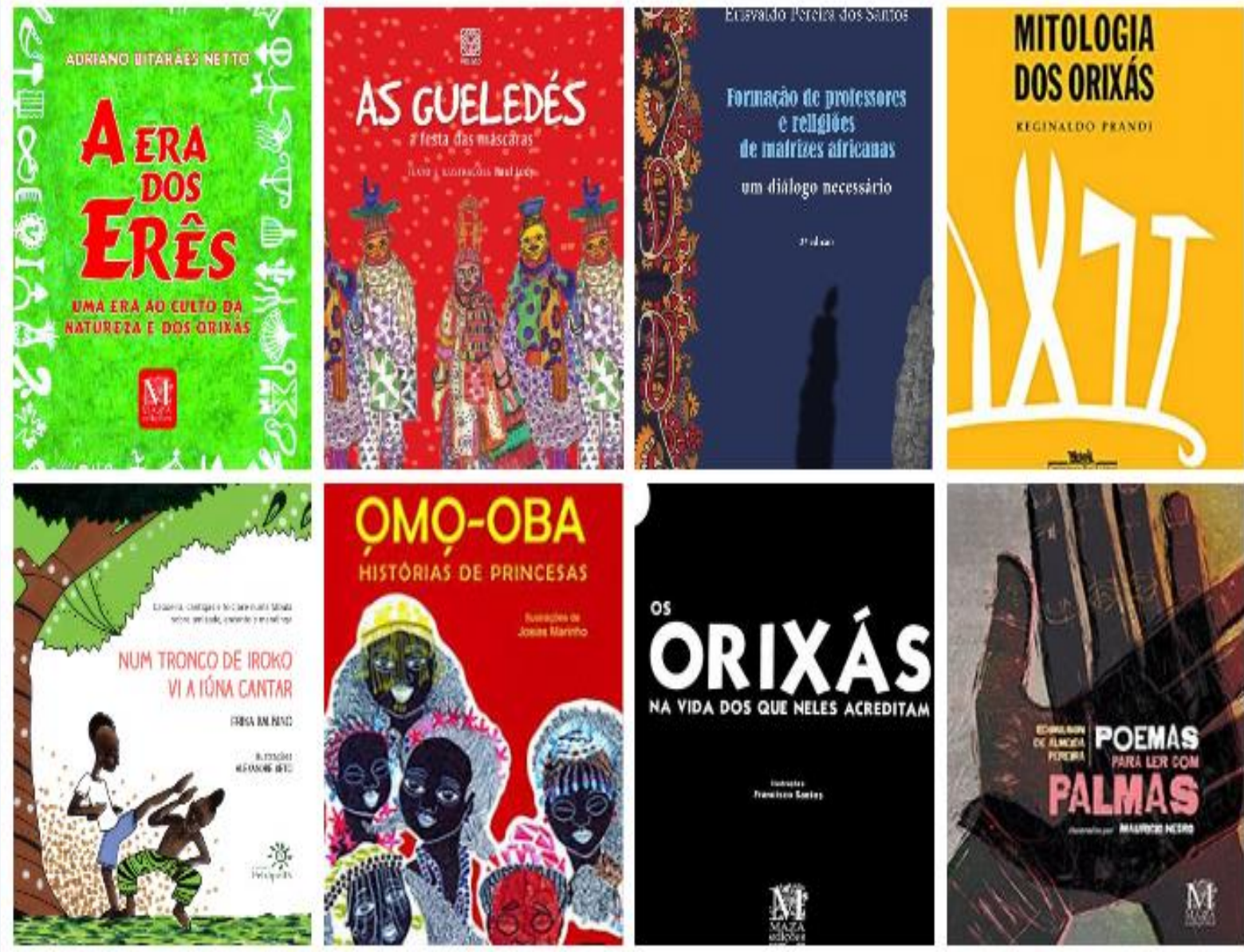

Fonte: Acervo pessoal do autor

Estas são algumas obras literárias que foram elencadas pelo pesquisador para compor sua Mala Temática. Todas as obras trazem em seu escopo importantes abordagens que enaltecem as culturas africanas e afro-brasileiras, podendo ser utilizadas pelos educadores para dramatizações, rodas de conversa, contação de histórias, produções de textos e, sobretudo, para resgatar o Axé como princípio da força vital, seguido pelo reconhecimento e importância da ancestralidade, circularidade, oralidade, musicalidade, corporeidade, ludicidade e cooperatividade como valores civilizatórios afro-brasileiros. 


\section{Considerações finais}

Construir um artefato cultural como recurso pedagógico que possa contribuir com a implementação da Lei 10.639/03 em escolas brasileiras não é tarefa fácil. Um dos desafios consiste em fazer com que os educadores encontrem nele a possibilidade de criação, uso, por isso, ele deve ser pensado como resultado de uma habilidade inovadora, dinâmica e atrativa para todos que forem utilizá-lo como recurso didático.

O produto apresentado trata-se de um exemplar preparado por um educador de escola pública para atender as exigências ao Programa de Mestrado Profissional da Universidade Federal de Minas Gerais (UFMG). Além disso, foi necessário que o produto respondesse aos problemas de pesquisa apresentados pelo pesquisador. $\mathrm{O}$ artefato cultural Mala Temática Mojubá, foi testado em escolas presentes na região metropolitana de Belo Horizonte/MG e apresentado em palestras de diversas instituições de ensino, dentre elas, algumas universidades.

Os resultados obtidos demonstraram que o produto confeccionado contribuiu para a descolonização religiosa nas escolas em que foi destinado, bem como apresentou formas de flexibilizar o currículo dessas instituições, além disso, a utilização da Mala Temática em instituições de ensino representou um excelente recurso para o enfrentamento à intolerância, ao racismo religioso e às discriminações presentes no dia a dia das salas de aula.

Cabe ressaltar que o produto ora apresentado, auxiliará os educadores com novas possibilidades de ensino e promoverá a melhora da autoestima dos sujeitos candomblecistas e umbandistas que participarem das atividades. Além disso, o desenvolvimento de trabalhos práticos envolvendo temas relacionados às religiões de matrizes africanas contribui com a descolonização do currículo e favorece a transdisciplinaridade, por meio do desenvolvimento de projetos educativos.

A escola possui um papel importante de desconstrução de preconceitos e de proselitismos e não pode ignorar a necessidade de pautar as questões referentes às culturas africanas e afro-brasileiras, perpassando pelas religiões de matrizes africanas e seus sujeitos de forma ética, sobretudo porque, estas questões, permeiam as vivências de pessoas rejeitadas na escola, podendo despertar-lhes, em consequência disso, o sentimento de "vergonha" de pertencer às religiões e culturas não hegemônicas.

O respeito às diferenças e aos diferentes passam pelo princípio da dignidade da pessoa humana, que implica o respeito aos direitos humanos e repudia qualquer tipo de discriminação. É preciso que, nas escolas, promovam-se o respeito às diferenças, a liberdade de expressão, a 
alteridade e, sobretudo, a garantia dos direitos humanos a todos e todas que diariamente travam uma verdadeira batalha para conquistá-los.

\section{REFERÊNCIAS}

BALBINO. Erika. Num tronco de Iroko vi a Iúna cantar. São Paulo; Petrópolis: 2014.

BAKKE. Rachel Rua Baptista. Na escola com os orixás: o ensino das religiões afrobrasileiras na aplicação da lei 10.639. 2011. 222 f. Doutorado - Programa de Pós-Graduação em Antropologia Social. Faculdade de Filosofia, Letras e Ciências Humanas da Universidade de São Paulo. Disponível em:

<www.teses.usp.br/teses/disponiveis/8/8134/.../2011_RachelRuaBaptistaBakke_VOrig.pdf>. Acesso em: 25 mai. 2020.

BRANDÃO, Ana Paula (coord.). Saberes e fazeres: modos de interagir. Rio de Janeiro: Vozes, 2008.

BRASIL. Lei de Diretrizes e Bases da Educação Nacional. Lei n. 9.9394, de 20 de dezembro de 1996. Brasília: Presidência da República, 1996. Disponível em: <www.planalto.gov.br/ccivil_03/Leis/L9394.htm>. Acesso em: Jun. 2020.

BRASIL. Ministério da Educação (MEC). Secretaria de Educação Fundamental (SEF). Parâmetros Curriculares Nacionais: introdução aos Parâmetros Curriculares Nacionais. Brasília, DF: MEC/SEF, 1997

BRASIL. Lei $\mathbf{n}^{\mathbf{0}} \mathbf{1 0 . 6 3 9}$, de 9 de janeiro de 2003. Altera a lei $\mathrm{n}^{\circ} 9.394$, de 20 de dezembro de 1996, que estabelece as diretrizes e bases da educação nacional, para incluir no currículo oficial da rede de ensino a obrigatoriedade da temática "História e Cultura Afro-brasileira", e dá outras providências. 2003.

BRASIL. CNE/CP Resolução n ${ }^{\circ} 1$ de 17 de março de 2004. Institui as Diretrizes Curriculares Nacionais para a Educação das Relações Étnico-Raciais e para o Ensino de História e Cultura Afro-Brasileira e Africana. 2004.

BRASIL. Lei no 11.635/2007. Instituição do Dia Nacional de Combate à Intolerância Religiosa. Disponível_em:_http://www2.camara.leg.br/legin/fed/ lei/2007/lei-11635-27dezembro-2007-567636-publicacaooriginal-90930-pl.html. Acesso em: 30 de junho de 2020.

BRASIL. Portaria normativa $\mathbf{n}^{0}$ 17, de 28 de dezembro de 2009. Dispõe sobre o mestrado profissional no âmbito da Fundação Coordenação de Aperfeiçoamento de Pessoal de Nível Superior - CAPES. Brasilia.2009.

CANDAU, Vera Maria (Org.). Reinventar a escola. Petrópolis, RJ: Vozes, 2000.

CAPUTO, Stela Guedes. Educação em terreiros e como a escola se relaciona com crianças que praticam candomblé. 01/07/2005 235 f. Doutorado em Educação. Instituição de Ensino: Pontifícia Universidade Católica do Rio de Janeiro, Rio de Janeiro Biblioteca Depositária. 
Disponível em: https://www.maxwell.vrac.puc-rio.br/7708/7708_1.PDF, acesso em: 01 junho. 2020.

CHAVES JUNIOR, Luiz Alberto. Identidade Candomblecista em Foco: a história de vida como axé pedagógico. 26/08/2015. 164 f. Mestrado em Educação - Instituição de Ensino: Universidade Federal do Estado do Rio de Janeiro, Rio de Janeiro. Biblioteca Depositária: Biblioteca Central da Universidade Federal do Estado do Rio de Janeiro. Disponível em: <http://www.unirio.br/ppgedu/dissertacoes/DissertaoPPGEduLuizAlbertoChavesJunior.pdf .> Acesso em: 20.mai.2020.

CHISTÉ, Priscila de Souza. Proposta de avaliação coletiva de materiais educativos em mestrados profissionais na área de ensino. Revista de Educacional Campo Abierto, v. 38, p. 185-198, 2019.

CONTAGEM. Lei n 4737, de 24 de junho de 2015. Plano Municipal de Educação.

Disponível: http://www.contagem.mg.gov.br/estudacontagem/wp-

content/uploads/2019/03/lei_047372015_pmecontagem.pdf. Acesso: 01 junho. 2020.

FRANCO. Maria Amélia Santoro. Pesquisa-Ação Pedagógica: práticas de empoderamento e de participação. Revista ETD - Educação Temática Digital, 18(2), 511-530. 2016.

KAPLÚN, Gabriel. Materiais educativos: experiência de aprendizado. Revista Comunicação \& Educação, 271, 46-60. 2003.

MCLAREN, Peter. Multiculturalismo Crítico. São Paulo; Cortez, 1997.

LODY, Raul. As gueledés: A festa das máscaras. Rio de Janeiro: Pallas, 2010.

NETTO, Adriano Bitarães. Aera dos Erês: uma Era ao culto da natureza e dos orixás. Belo Horizonte: Mazza Edições, 2010.

OLIVEIRA. Ariene Gomes de. Educação nos Terreiros de Caruaru/Pernambuco: um encontro com a tradição africana através dos Orixás. 2014 213f. Mestrado - Programa de PósGraduação em Educação Contemporânea. Universidade Federal de Pernambuco. Disponível em https://repositorio.ufpe.br/handle/123456789/11280. Acesso em: 03 jun.2020.

OLIVEIRA, Kiusam. Omo-Oba: histórias de princesas. Belo Horizonte: Mazza Edições, 2009.

ONU. Declaração Universal Dos Direitos Humanos. Rio de Janeiro: UNIC, 2009 [1948]. Disponível em: <http://www.dudh.org.br/wp-content/uploads/2014/12/dudh.pdf> Acesso em: 5 jun. 2020.

PAIVA, Jacyara Silva de. Caminhos do Educador Social no Brasil. Paco Editorial. 2015.

PEREIRA. Edmilson de Almeida. Poemas para ler com as mãos. Belo Horizonte: Mazza Edições, 2017.

PRANDI, Reginaldo. Mitologia dos Orixás. São Paulo: Companhia das letras, 2001. 
SANTOS, Boaventura de Sousa. Para além do pensamento abissal: das linhas globais a uma ecologia de saberes. In: SANTOS, Boaventura de Sousa e MENEZES, Maria Paula (Org.). Epistemologias do Sul. Coimbra: Ed. Almedina, 2009.

SANTOS, Erisvaldo Pereira dos. Formação de professores e religiões de matrizes Africanas: um diálogo necessário. 2.ed. Belo Horizonte: Nandyala, 2015.

SACRISTÁN. Gimeno J. Currículo e diversidade cultural. In: SILVA, Tomaz Tadeu; MOREIRA, Antônio Flávio. Territórios Contestados. Petrópolis, Vozes 1995.

SILVA, Tomaz Tadeu da. Alienígenas na Sala de Aula: uma introdução aos estudos culturais em educação. Petrópolis, Rio de Janeiro: Vozes, 1995.

SILVA, Tomaz Tadeu da. Documentos de Identidade: uma introdução às teorias do currículo. 3 ed. Belo Horizonte: Autêntica, 2016.

SIQUEIRA. Maria de Lourdes. Os orixás na vida dos que neles acreditam. Belo Horizonte. Mazza Edições. 1995.

VIEIRA, Maurício Benedito da Silva. As religiões de matrizes africanas no contexto da efetivação da lei 10.639/03 em Cuiabá-MT. 2016102 f. Mestrado em Educação - Instituição de Ensino: Universidade Federal de mato Grosso, Cuiabá. Biblioteca Depositária: Biblioteca Setorial do Instituto de Educação e Biblioteca Central / IE / UFMT. Disponível em http://www.ufmt.br/ufmt/site/noticia/visualizar/28822/Cuiaba. Acesso em 06 jun. 2020.

\section{SOBRE OS AUTORES:}

\section{Sérgio Teixeira da Silva}

Mestre em Educação pela Universidade Federal de Minas Gerais. Possui graduação em Geografia pela Pontifícia Universidade Católica de MG (2001). Atualmente é professor de Educação Básica na Rede Municipal de Ensino de Contagem/MG. Lattes: http://lattes.cnpq.br/1730666570274824. E-mail: sergioandreprofessor@gmail.com

(iD https://orcid.org/0000-0002-7896-7372

\section{Alexandre Gomes Soares}

Pós-doutorando em Educação pela Universidade Federal de Minas Gerais (UFMG). Doutor em Educação pela Universidade de São Paulo (USP). Mestre em Educação Tecnológica pelo Centro Federal de Educação Tecnológica de Minas Gerais (CEFET-MG). Coordenador Pedagógico $1^{\mathrm{o}}$ e $2^{\mathrm{o}}$ Ciclos na Prefeitura de Belo Horizonte. Lattes: http://lattes.cnpq.br/2280707646300775. E-mail: prof.alexhis@gmail.com

iD https://orcid.org/0000-0001-6835-1155 